\title{
From Brain Ischemia to Alzheimer-Like Neurodegeneration
}

\author{
Ryszard Pluta ${ }^{1, \dagger}$, Marzena Ułamek-Kozioł',2, Sławomir Januszewski', Stanisław J. Czuczwar ${ }^{3}$
}

\begin{abstract}
Latest studies have revealed a key role of ischemic brain episodes in Alzheimer-like neurodegeneration and dementia development. This review presents the current progress in understanding how brain ischemia may promote Alzheimer's disease pathological changes and cognitive impairment. It seems that brain ischemia promotes Alzheimer's disease-like neurodegeneration development through various mechanisms, including accumulation and aggravation of different parts of amyloid protein precursor, tau protein phosphorylation, dysregulation of Alzheimer-related genes, neuroinflammation, neuronal loss, synaptic dysfunction, white matter lesion and general brain atrophy. Progress in understanding key mechanisms of ischemia-induced changes of Alzheimer-phenotype will help develop preventing and treating strategies against sporadic Alzheimer's disease pathology and dementia generated by sublethal and/or silent ischemia.
\end{abstract}

\section{Keywords}

Alzheimer's disease, Brain ischemia, Amyloid protein precursor, Tau protein, Neurodegeneration, Genes

\section{Introduction}

Nowadays sporadic Alzheimer's disease presents the largest part of dementia in an aging society. Alzheimer's disease is described pathologically by progressive neurodegeneration which leads to development of cognitive impairment in patients with hippocampal atrophy. Characteristic elements of this disease comprise extraneuronal senile plaques proudest by $\beta$-amyloid peptides 1-40 and 1-42 together with intraneuronal neurofibrillary tangles generated by phosphorylation of tau protein in the brain. There is no cure and current therapies are not effective in delaying progression of Alzheimer's disease. This disorder is a real medical, social, and economic burden in the present society for the reason that population is rapidly aging $[1,2]$.
Postischemic Alzheimer-type dementia is the second most common form of dementia [3]. In fact, Alzheimer's disease and postischemic dementia often coexist in aging patients with dementia [4]. It is calculated approximately that circa $40 \%$ of Alzheimer's disease subjects have mixed dementia [3]. Patients with postischemic brain injury frequently have cognitive deficits to diverse degrees [5,6]. Experimental animals after ischemia-reperfusion exhibit cognitive deficits, too [7-10]. The key role of episodic brain ischemia in dementia development has appeared to the forehead of clinical investigation [11-21]. Investigations in the last 25 years have suggested that ischemic brain injury might promote Alzheimer-type neurodegeneration through generation of reactive oxygen species [20,22], by neuronal energy failure,

\footnotetext{
'Laboratory of Ischemic and Neurodegenerative Brain Research, Mossakowski Medical Research Centre, Polish Academy of Sciences, Warsaw, Poland

${ }^{2}$ First Department of Neurology, Institute of Psychiatry and Neurology, Warsaw, Poland

${ }^{3}$ Department of Pathophysiology, Medical University of Lublin, Lublin, Poland

${ }^{\dagger}$ Author for correspondence: Prof. Ryszard Pluta, Laboratory of Ischemic and Neurodegenerative Brain Research, Mossakowski Medical Research Centre, Polish Academy of Sciences, 02-106 Warsaw, Pawińskiego 5 Str., Poland, Tel: 48-22-6086-540; fax: 48-22-668-55-32; email: pluta@imdik.pan.pl
} 
development of inflammation through activated glial cells [22-25] and different parts of amyloid protein precursor accumulation [12,22] and tau protein pathology [26], that in turn, damage the neuronal cells especially in hippocampus and contribute to white matter lesions [27-30]. This review tries to present the current progress focusing on brain ischemia-reperfusion-induced Alzheimer's disease-like neurodegeneration and dementia.

\section{Mechanisms of Action Triggering Ischemic Alzheimer-like Pathology}

Alzheimer's disease comprises two forms: earlyonset Alzheimer's disease with prevalence of circa $5 \%$ that is caused by mutations of genes encoding amyloid protein precursor and/or presenilins, and over 95\% of late-onset Alzheimer's disease cases which are called of sporadic nature. The most important risk factor for sporadic Alzheimer's disease is aging, and lastly the most supported by a good number of scientists cause of Alzheimer's disease is brain ischemia closely associated with age [11-21]. Despite of years of expand, first theory of Alzheimer's disease cause, the amyloid cascade hypothesis, did not resolve the etiology and disease treatment and current studies suggest that ischemic brain injury promotes Alzheimer's disease-like neurodegeneration through numerous molecular mechanisms as presented below.

\section{Accumulation of Amyloid after Brain Ischemia}

$\beta$-amyloid peptides 1-40 and 1-42 which are components of amyloid plaques are produced from amyloid protein precursor through proteolytic cleavages by $\beta$ - and $\gamma$-secretases. Amyloid deposits occur both in the brain tissue and in the walls of vessels in Alzheimer's disease and in the brains following ischemic injury in animals and humans [12,22,31-34]. Animals with short term survival (2-7 days) after ischemiareperfusion brain injury, showed intense brain immunoreactivity to the C-terminal of amyloid protein precursor and to the $\beta$-amyloid peptide and to the $\mathrm{N}$-terminal of amyloid protein precursor as well. The staining was identified intra- and extracellularly [12,22]. Different parts of amyloid protein precursor were noted within neuronal and gilal cells. Staining was seen mainly in undamaged neurons. After 6-12 months follwing brain ischemia injury, an increased immunoreactivity only to $\beta$-amyloid peptide and C-terminal of amyloid protein precursor was observed [22-24,35]. Extracellular various parts of amyloid protein precursor deposits ranged from widespread small dots to irregular diffuse plaques [12,22,36-40]. Widespread and multifocal diffuse plaques predominated in the hippocampus, entorhinal cortex, corpus callosum, around the lateral ventricles and thalamus. Glial and neuronal cells have been found frequently inside diffuse extracellular plaques. Time-dependent collection of $\beta$-amyloid peptide in the hippocampus, especially in the areas with open blood-brain barrier in rats, occurs after brain ischemia [27,28,41-45]. It should be emphasized that the $\beta$-amyloid peptide deposits as seen in animals up to 2 years after transient brain ischemia cannot be stained with thioflavine $S[12,46]$ but in humans, the opposite situation after brain ischemia was present as regards thioflavine S staining [32]. Some of evidences have showed that brain ischemia upregulates $\beta$ - and $\gamma$-secretase-mediated amyloid protein precursor cleavage $[12,19,20,38,40,47-50]$. It is possible that brain ischemia upregulates amyloid protein precursor processing and leads to $\beta$-amyloid peptide accumulation by activation of gene expression of $\beta$-secretase and presenilin 1 and 2, leading consequently to increases in the secretase level and its activity [50-52]. The amyloid accumulation in vessel walls caused by ischemic brain injury with vessel spasm could further induce ischemic lesion and develop a self-propelling vicious circle of ischemic episodes and finally lead to irreversible damage of brain tissue $[22,53]$.

\section{Hyperphosphorylation of Tau Protein after Brain Ischemia}

The microtubule-associated tau protein becomes abnormally hyperphosphorylated in Alzheimer's disease patient's brains and finally generates intraneuronal neurofibrillary tangles which are crucial in progressing Alzheimer's disease pathology. Cyclin dependent kinase 5 $(\mathrm{Cdk} 5)$ is involved in neurofibrillary tanglelike tauopathy induced by ischemic tau protein hyperphosphorylation [26] and tau protein phosphorylation at numerous Alzheimer's disease specific sites caused by experimental focal brain ischemia was observed, too [54]. Increased tau protein phosphorylation with parallel activation of Cdk5, calcium/calmodulindependent protein kinase II (CaMK-II), and glycogen synthase kinase-3b (GSK-3b), as well as inhibition of protein phosphatase $2 \mathrm{~A}$ (PP2A) was noted in a rat model of focal brain ischemia 
[55]. It is thus reasonable to suggest that the increased tau protein phosphorylation and $\beta$-amyloid peptide overproduction appear to be very sensitive to brain ischemia.

\section{Dysregulation of Alzheimer's-Related Genes after Brain Ischemia}

After transient focal ischemic brain injury, amyloid protein precursor gene was upregulated in the penumbra and infarct core during seven days of recirculation [56-58]. In the rat CA1 subfield of hippocampus, the expression of amyloid protein precursor gene was decreased below control value during 2 days following ischemic brain injury [50]. Seven and 30 days following brain ischemia, the amyloid protein precursor gene expression increased above control value [50]. In temporal cortex, the expression of amyloid protein precursor gene was reduced below control value 2 days after brain ischemia [51]. However, 7 and 30 days after ischemic injury, the amyloid protein precursor gene expression was increased above control [51].

In experimental ischemic brain injury, down expression of $\alpha$-secretase gene was noted [59]. Ye et al. [60] noted the dysregulated expression of $\beta$-secretase gene after ischemic brain injury. This expression increased in the hippocampus and cortex during recirculation [60]. $\beta$-secretase gene expression increased above control value following brain ischemia in the rat CA1 area of hippocampus 2-7 days after injury [50]. But 30 days following brain ischemia, $\beta$-secretase gene expression decreased below control value [50]. $\beta$-secretase gene expression was upregulated in the temporal cortex 2 days following brain ischemia [51]. Seven and thirty days following temporal cortex ischemia, $\beta$-secretase gene expression was significantly down regulated [51].

The increased overexpression of presenilin-1 gene was observed on day 3 after transient brain ischemia in neurons of the CA3 area of gerbil hippocampus [61]. Expression of presenilins after local ischemic brain injury was upregulated in the rat hippocampus and cortex [62]. In the rat CA1 subfield of hippocampus, presenilin 1 and 2 gene expression was above control value 2 and 7 days following complete brain ischemia [50]. But 30 days following the ischemic injury, presenilin 1 and 2 gene expression decreased below control value [50]. In the temporal cortex, presenilin 1 gene expression decreased below control value but presenilin 2 increased above control 2 days following brain ischemia [52]. Seven days after brain ischemia, presenilin 1 gene expression was down regulated and presenilin 2 was significantly elevated [52]. Thirty days, following brain ischemia presenilin 1 gene expression increased above control value and presenilin 2 was reduced below control [52].

It was found that autophagy gene in hippocampus CA1 area was not significantly modified 2, 7 and 30 days after brain ischemia. But mitophagy gene was significantly upregulated at day 2 and decreased below the basal values at days 7 and 30 [63]. The gene expression of caspase 3 in hippocampus CA1 area 2 days after ischemic brain injury increased by more than $300 \%$ comparing to the basal level. But 7 days after ischemia, its expression was close to the basal value. Thirty days after brain ischemic injury, in the above area the gene expression was reduced below the basal value [63].

In the temporal cortex, autophagy gene expression increased during 2-30 days following transient ischemic brain injury in rats $[64,65]$. But mitophagy gene decreased below normal value 2 days after brain ischemia. Seven and thirty days after ischemic injury, mitophagy gene expression increased above control values. Apoptotic gene caspase 3 expressions were reduced below normal value 2 days following brain ischemia. Seven and thirty days following ischemia, caspase 3 gene expression increased above control values [64].

\section{Neuronal Loss after Brain Ischemia}

Neuronal and synaptic loss in Alzheimer's disease cases correlates directly to the severity degree of dementia [66]. Hippocampus pathology with necrotic and apoptotic neuronal cells is seen in the CA1 subfield of hippocampus 2-7 days after brain ischemia [22,35]. At 2 days, neuronal loss was superimposed with damaged neuronal cells. In later stages (7 days and 6 months), the number of neuronal cells with abnormal changes was reduced being replaced by neurons loss. Above changes were localized mainly in hippocampus and third cortical layer. Borderline zones of the cerebral cortex were also the site of severe pathology. Six months following ischemic brain injury in addition to localized neuronal loss different types of pathological changes of neurons were noted. The first one took the form of chronic neuronal degeneration which was observed in the early stage after ischemia. Other changes were of a nature typical for the 
early ischemic changes but they were observed in those areas of the brain that were not involved in early damage, e.g., the CA2, CA3, and CA4 subfields of hippocampus [22]. The neuronal death in the CA1 area, together with the decrease of acetylcholine level in the cortex and striatum is evident following focal brain ischemia, suggests that the neuronal disappearance might result from insufficiency of neuronal excitatory transmission $[66,67]$.

\section{Synaptic Dysfunction after Brain Ischemia}

Synaptic integrity of brain is necessary for physiological functions, including memory and learning. Decreased levels of both synaptophysin and postsynaptic density protein 95 have been found in rat hippocampus following local brain ischemia $[42,54]$. Likewise, these rats presented synaptic ultrastructural changes in the CA1 area of the hippocampus. Other study has shown that ischemic brain injury generates an increase in synaptic autophagy and asymmetric synapses, which may be connected with neuronal death in the CA1 area of hippocampus after transient ischemia $[65,68,69]$. There are experimental evidences of isolated and persistent synaptic malfunction resulting from transient brain ischemia [70]. Depression of excitatory synaptic transmission in ischemic condition was shown in CA1 area of hippocampus [67]. The ischemia induced intracellular $\mathrm{Ca}^{2+}$ increase upregulates calpain's activity in neurons and calpain target proteins are present in GABAergic and glutamatergic synapses. In brain ischemia, calpains cleave pre- and postsynaptic proteins. Calpain-mediated protein cleavage contributes to neuronal death in brain ischemia [71].

\section{White Matter Lesion and Inflammation after Brain Ischemia}

White matter lesion and glia activation are seen in both animal and human brains following brain ischemia $[22,25,27,28,35,72-74]$. In rat models, brain ischemia appears to cause more severe white matter changes in the subcortical white matter and corpus callosum $[22,27,28,75]$. These findings are consistent with the glia activation in the corpus callosum after ischemic brain injury [76]. Brain ischemia promotes increased permeability of blood-brain barrier that facilitates the entry of inflammatory cells into the brain tissue and the release of a large number of serine proteases as well as $\beta$-amyloid peptides from blood into brain parenychma, what in turn leads to white matter lesion [25,41,44,77-80].

\section{Ischemia-Induced Brain Atrophy}

Some evidences indicate that transient ischemic brain injury in rats caused widespread neuronal loss, in structures belonging or not to selectively vulnerable areas of the brain [22,35]. The ischemic brain changes represent a gradually progressing process extending over a long period during reperfusion after the ischemic episode [22]. The nature of the neuropathological processes is indicated by the changes in the brain occurring during ischemic period and two years of survival [22]. They are characteristic not only for the early brain changes, but for an active pathological process in the late stage after ischemia as well. One/two year(s) after ischemia, the pathological process results in generalized brain atrophy $[22,35,81]$. Gross examination, conducted between 9 and 24 months after ischemic brain injury, demonstrated hydrocephalic hallmarks of brain $[35,81]$. Dilatation of the subarachnoid space around the brain hemispheres was observed, too [35]. Complete atrophy of hippocampus with massive pyramidal neuronal disappearance in the pyramidal layer of the hippocampal CA1 subfield and atrophy of the striatum were noted [35]. Cerebral cortex was narrow showing increased neuronal density. An additional feature of late brain atrophy was manifested as diffuse white matter lesions taking the form of rarefaction and cavitations, revealing advanced spongiosis. This phenomenon may be explained by massive neuronal loss with accompanying increased blood-brain barrier permeability occurring in the early and late stages following brain ischemia [41].

\section{Conclusions}

Brain ischemia is common in the old persons and frequently contributes to neurodegeneration, dementia, and probably to sporadic Alzheimer's disease development. As discussed in this review, many investigations have shown a causative role of ischemic brain episodes in Alzheimer-like neurodegeneration. On the other hand, there are data showing ischemic lesions in Alzheimer's disease brains and Alzheimer's lesions in experimental ischemic brains [4,82,83]. It should be emphasized that the brain ischemiapromoted neurodegeneration is connected with $\beta$-amyloid peptide generation and tau protein hyperphosphorylation suggesting that 
the ischemic neurons degeneration/loss might be caused by or associated with abnormal $\beta$-amyloid peptide production and tau protein hyperphosphorylation $[12,26,50,51,54,57,58]$. This review presents evidences that the brain ischemia promotes solid dysregulation of Alzheimer's-related genes and proteins and neurodegenerative epigenetic markers, which may be part of additional neuropathogenic factors contributing to the neuropathology of ischemia and dementia with Alzheimer's phenotype [50,51,52,57,58,64]. In summary, experimental data on postischemic brain injury show that Alzheimer's disease-related peptides (e.g. $\beta$-amyloid peptide) and/or proteins (e.g. tau protein) render the brain tissue more susceptible to brain ischemic pathology, resulting in the generation of neurodegenerative abnormalities like dementia. Alzheimer's disease-related factors at the same time sensitize the brain to ischemic neurodegeneration and lower the threshold of ischemic brain pathology in vivo. We propose that ischemia-reperfusion processes in brain are the fountainhead of a cycle of genetic, molecular and cellular events that have neurodegenerative consequences, finally leading to Alzheimer's disease. We speculate that Alzheimer's disease may be caused by repeated sublethal and silent ischemia-reperfusion alterations that attack and slowly steal the minds of their victims. Ischemic changes in areas destroyed by Alzheimer's disease neuropathological processes may contribute to dementia of Alzheimer's disease individuals. It is tempting to speculate that Alzheimer's disease is a byproduct of ischemia-reperfusion-induced overexpression of amyloid protein precursor, $\beta$ - and $\gamma$-secretase genes in the brain. Such data convinces us of the need for future study efforts in this exciting, interesting and new very significant field of experimental investigations. On the other hand, ischemic brain injury provides a bridge between clinical and experimental research that greatly facilitates the interpretation of complex disorder processes including Alzheimer-type dementia.

Future studies should focus on searching for the major and more important molecular/genetic mechanisms by which brain ischemia causes cognitive impairment and neurodegeneration of Alzheimer's-type. This study has been intended to find potential treatment targets to prevent and cure ischemic dementia with Alzheimerphenotype and possibly, also Alzheimer's disease. Whether brain ischemia is directly involved in the pathogenesis of Alzheimer's disease or acts indirectly as a contributor to the chain of negative events, needs to be established. Nevertheless, prevention and treatment of ischemic brain injury antecedents may have important implications for Alzheimer's disease. In view of the above-mentioned observations that cognitive decline is progressing after brain ischemia, there is a distinct possibility that we can prevent this decline by targeting the slowly progressing neurodegeneration, following the ischemic brain injury by aiming at molecular events now shown to be triggered by brain ischemia. These approaches could include individual or combined treatments, possibly targetting brain $\beta$-amyloid peptide generation, tau protein phosphorylation, brain inflammation and neuronal loss.

\section{Conflict of Interest}

Author declares no conflict of interest

Acknowledgements
The authors acknowledge the support provided by
the Mossakowski Medical Research Centre, Polish
Academy of Sciences, Poland (T3-RP), and by the
statutory grants from the Medical University in
Lublin, Poland (SJC).

\section{References}

1. Scheltens $P$, Blennow $K$, Breteler MMB, et al. Alzheimer's disease. Lancet 388(1), 505-517 (2016).

2. Gustavsson A, Green C, Jones RW, et al. Current issues and future research priorities for health economic modelling across the full continuum of Alzheimer's disease. Alzheimers. Dement 13(3), 312-321 (2017)

3. Battistin L, Cagnin A. Vascular cognitive disorder. A biological and clinical overview. Neurochem. Res 35(12), 1933-1938 (2010).
4. Snowdon DA, Greiner LH, Mortimer JA, et al. Brain infarction and the clinical expression of Alzheimer disease: The nun study. JAMA 277(10), 813-817 (1997).

5. Ruitenberg A, den Heijer T, Bakker SL, et al. Cerebral hypoperfusion and clinical onset of dementia: the Rotterdam Study. Ann. Neurol 57(6), 789-794 (2005).

6. Pinkston JB, Alekseeva N, Toledo EG. Stroke and dementia. Neurol. Res 31(8), 824-831 (2009).

7. de la Tremblaye PB, Plamondon H. Impaired conditioned emotional response and object recognition are concomitant to neuronal damage in the amygdala and perirhinal cortex in middle-aged ischemic rats. Behav. Brain. Res 219(2), 227-233 (2011).

8. Kiryk A, Pluta R, Figiel I, et al. Transient brain ischemia due to cardiac arrest causes irreversible long-lasting cognitive injury. Behav. Brain. Res 219(1), 1-7 (2011).

9. Li J, Wang YJ, Zhang M, et al. Cerebral ischemia aggravates cognitive impairment in a rat model of Alzheimer's disease. Life. Sci 89(3-4), 86-92 (2011). 
10. Cohan CH, Neumann JT, Dave KR, et al. Effect of cardiac arrest on cognitive impairment and hippocampal plasticity in middle-aged rats. PLoSOne 10(5), e0124918 (2015).

11. Pluta R. Resuscitation of the rabbit brain after acute complete ischemia lasting up to $1 \mathrm{~h}$. Pathophysiological and pathomorphological observations. Resuscitation 15(1), 267-287 (1987).

12. Pluta R, Kida E, Lossinsky AS, et al. Complete cerebral ischemia with shortterm survival in rats induced by cardiac arrest: I. Extracellular accumulation of Alzheimer's $\beta$-amyloid protein precursor in the brain. Brain. Res 649(1), 323-328 (1994).

13. Pluta R. From brain ischemia-reperfusion injury to possible sporadic Alzheimer's disease. Curr. Neurovasc. Res 1(5), 441-453 (2004).

14. Pluta R. Is the ischemic blood-brain barrier insufficiency responsible for full-blown Alzheimer's disease? Neurol. Res 28(6), 266271 (2006).

15. Pluta R. Role of ischemic blood-brain barrier on amyloid plaques development in Alzheimer's disease brain. Curr. Neurovasc. Res 4(5), 121-129 (2007)

16. Pluta R, Kocki J, Maciejewski R, et al. Ischemia signalling to Alzheimer-related genes. Folia Neuropathol, 50(4), 322-329 (2012).

17. Akinyemi RO, Mukaetova-Ladinska EB, Attems J, et al. Vascular risk factors and neurodegeneration in ageing related dementias: Alzheimer's disease and vascular dementia. Curr. Alzheimer. Res 10(6), 642-653 (2013).

18. Kelleher RJ, Soiza RL. Evidence of endothelial dysfunction in the development of Alzheimer's disease: is Alzheimer's a vascular disorder? Am. J. Cardiovasc. Dis 3(4), 197-226 (2013).

19. Pluta R, Furmaga-Jabłońska W, Maciejewsk $R$, et al. Brain ischemia activates beta- and gamma secretase cleavage of amyloid precursor protein: significance in sporadic Alzheimer's disease. Mol. Neurobiol 47(1), 425-434 (2013)

20. Pluta R, Jabłoński M, Ułamek-Kozioł M, et al. Sporadic Alzheimer'sdisease begins as episodes of brain ischemia and ischemically dysregulated Alzheimer's disease genes. Mol. Neurobiol 48(3), 500-515 (2013).

21. Roh JH, Lee JH. Recent updates on subcortical ischemic vascular dementia. J. Stroke 16(1), 18-26 (2014).

22. Pluta R, Ułamek M, Jabłoński M. Alzheimer's mechanisms in ischemic brain degeneration. Anat. Rec 292(12), 1863-1881 (2009).

23. Pluta R. Glial expression of the $\beta$-amyloid peptide in cardiac arrest. J. Neurol. SCi 204(1), 277-280 (2002).

24. Pluta R. Astroglial expression of the betaamyloid in ischemia-reperfusion brain injury. Ann. NY. Acad. Sci 977(1), 102-108 (2002).

25.Sekeljic V, Bataveljic D, Stamenkovic S et al. Cellular markers of neuroinflammation and neurogenesis after ischemic brain injury in the long-term survival rat model. Brain. Struct. Funct 217(2), 411-420 (2012).

26. Wen $Y$, Yang $\mathrm{SH}$, Liu R, et al. Cdk5 is involved in NFT-like tauopathy induced by transient cerebral ischemia in female rats. Biochim. Biophys. Acta 1772(4), 473-483 (2007).

27. Pluta R, Ułamek M, Januszewski S. Microblood-brain barrier openings and cytotoxic fragments of amyloid precursor protein accumulation in white matter after ischemic brain injury in long-lived rats. Acta. Neurochir 96 (Suppl.), 267-271 (2006).

28. Pluta R, Januszewski S, Ułamek M. Ischemic blood-brain barrier and amyloid in white matter as etiological factors in leukoaraiosis. Acta. Neurochir 102(Suppl.), 353-356 (2008).

29. Urabe T. Molecular mechanism and new protective strategy for ischemic white matter damages. Rinsho. Shinkeigaku 52(11), 908-910 (2012).

30. Bang J, Jeon WK, Lee IS, et al. Biphasic functional regulation in hippocampus of rat with chronic cerebral hypoperfusion induced by permanent occlusion of bilateral common carotid artery. PLoSOne 8(1), e70093 (2013).

31. Jendroska K, Poewe W, Daniel SE, et al. Ischemic stress induces deposition of amyloid beta immunoreactivity in human brain. Acta. Neuropathol 90(1), 461-466 (1995).

32. Wisniewski HM, Maślinska D. Beta-protein immunoreactivity in the human brain after cardiac arrest. Folia. Neuropathol 34(2), 6571 (1996).

33. Qi J, Wu H, Yang Y, et al. Cerebral ischemia and Alzheimer's disease: the expression of amyloid- $\beta$ and apolipoprotein $E$ in human hippocampus. J. Alzheimer's. Dis 12(4), 335341 (2007).

34. Maślińska D, Laure-Kamionowska M Taraszewska A, et al. Immunodistribution of amyloid beta protein $(A \beta)$ and advanced glycation end-product receptors (RAGE) in choroid plexus and ependyma of resuscitated patients. Folia. Neuropathol 49(4), 295-300 (2011).

35. Pluta R. The role of apolipoprotein $E$ in the deposition of $\beta$-amyloid peptide during ischemia-reperfusion brain injury. A model of early Alzheimer's disease. Ann. NY. Acad.
Sci 903(1), 324-334 (2000).

36. Hall ED, Oostveen JA, Dunn E, et al. Increased amyloid protein precursor and apolipoprotein $\mathrm{E}$ immunoreactivity in the selectively vulnerable hippocampus following transient forebrain ischemia in gerbils. Exp. Neurol 135(1), 17-27 (1995).

37. Yokota M, Saido TC, Tani E, et al. Cytotoxic fragment of amyloid precursor protein accumulates in hippocampus after global forebrain ischemia. J. Cereb. Blood. Flow. Metab 16(6), 1219-1223 (1996).

38. Ishimaru H, Ishikawa K, Haga S, et al. Accumulation of apolipoprotein $\mathrm{E}$ and $\beta$-amyloid-like protein in a trace of the hippocampal CA1 pyramidal cell layer after ischaemic delayed neuronal death. NeuroReport 7(18), 3063-3067 (1996).

39. Lin B, Schmidt-Kastner R, Busto R, et al. Progressive parenchymal deposition of $\beta$-amyloid precursor protein in rat brain following global cerebral ischemia. Acta. Neuropathol 97(1), 359-368 (1999).

40. Sinigaglia-Coimbra R, Cavalheiro EA Coimbra CG. Postischemic hypertermia induces Alzheimer-like pathology in the rat brain. Acta. Neuropathol 103(5), 444-452 (2002).

41. Pluta R, Januszewski S, Jabłoński M, et al. Factors in creepy delayed neuronal death in hippocampus following brain ischemiareperfusion injury with long-term survival. Acta. Neurochir 106(Suppl), 37-41 (2010).

42. Wang $X$, Xing A, Xu C, et al. Cerebrovascular hypoperfusion induces spatial memory impairment, synaptic changes, and amyloid-beta oligomerization in rats. J. Alzheimers. Dis 21(3), 813-822 (2010).

43. Pluta R. Blood-brain-barrier dysfunction and amyloid precursor protein accumulation in microvascular compartment following ischemia-reperfusion brain injury with 1-year survival. Acta. Neurochir 86(Suppl.), 117-122 (2003).

44. Pluta R. Pathological opening of the blood-brain barrier to horseradish peroxidase and amyloid precursor protein following ischemia-reperfusion brain injury. Chemotherapy 51(2), 223-226 (2005).

45. Mossakowski MJ, Lossinsky AS, Pluta R, et al. Abnormalities of the blood brain barrier in global cerebral ischemia in rats due to experimental cardiac arrest. Acta. Neurochir 60(Suppl.), 274-276 (1994).

46. van Groen T, Puurunen K, Maki HM, et al. Transformation of diffuse beta-amyloid precursor protein and beta-amyloid deposits to plaques in the thalamus after transient occlusion of the middle cerebral artery in rats. Stroke 36(7), 1551-1556 (2005).

47. Li L, Zhang X, Yang D, et al. Hypoxia 
increases Abeta generation by altering betaand gamma cleavage of APP. Neurobiol. Aging 30(7), 1091-1098 (2009).

48. Zhiyou C, Yong Y, Shanquan S, et al. Upregulation of BACE1 and beta-amyloid protein mediated by chronic cerebral hypoperfusion contributes to cognitive impairment and pathogenesis of Alzheimer's disease. Neurochem. Res 34(1), 1226-1235 (2009).

49. Koike MA, Green KN, Blurton-Jones M, et al. Oligemic hypoperfusion differentially affects tau and amyloid-beta. Am. J. Pathol 177(1), 300-310 (2010).

50. Kocki J, Ułamek-Kozioł M, Bogucka-Kocka $A$, et al. Dysregulation of amyloid- $\beta$ protein precursor, $\beta$-secretase, presenilin 1 and 2 genes in the rat selectively vulnerable CA1 subfield of hippocampus following transient global brain ischemia. J. Alzheimer's. Dis 47(4) 1047-1056 (2015).

51. Pluta R, Kocki J, Ułamek-Kozioł M, et al. Discrepancy in expression of $\beta$-secretase and amyloid- $\beta$ protein precursor in Alzheimerrelated genes in the rat medial temporal lobe cortex following transient global brain ischemia. J. Alzheimers. Dis 51(4), 1023-1031 (2016).

52. Pluta R, Kocki J, Ułamek-Kozioł M, et al. Alzheimer-associated presenilin 2 gene is dysregulated in rat medial temporal lobe cortex after complete brain ischemia due to cardiac arrest. Pharmacol. Rep 68(1), 155-161 (2016).

53. Wiśniewski HM, Pluta R, Lossinsky AS, et al. Ultrastructural studies of cerebral vascular spasm after cardiac arrest-related global cerebral ischemia in rats. Acta. Neuropathol 90(1), 432-440 (1995).

54. Zhao Y, Gu JH, Dai CL, et al. Chronic cerebral hypoperfusion causes decrease of O-GIcNAcylation, hyperphosphorylation of tau and behavioral deficits in mice. Front. Aging. Neurosci 6(1), 10 (2014).

55. Yao ZH, Zhang JJ, Xie XF. Enriched environment prevents cognitive impairment and tau hyperphosphorylation after chronic cerebral hypoperfusion. Curr. Neurovasc. Res 9(3), 176-184 (2012).

56. Shi J, Yang SH, Stubley L, et al. Hypoperfusion induces overexpression of $\beta$-amyloid precursor protein $m R N A$ in a focal ischemic rodent model. Brain. Res 853(1), 1-4 (2000).

57. Ułamek-Kozioł M, Pluta R, Bogucka-Kocka $A$, et al. Brain ischemia with Alzheimer phenotype dysregulates Alzheimer's diseaserelated proteins. Pharmacol. Rep 68(1), 582591 (2016).

58. Ułamek-Kozioł M, Pluta R, Januszewski $S$, Kocki J, et al. Expression of Alzheimer's disease risk genes in ischemic brain degeneration. Pharmacol. Rep 68(6), 13451349 (2016).

59. Yan $\mathrm{FL}$, Zhang J, Guan XN, et al. mRNA expression and activity of ADAM17 in hippocampus after chronic cerebral hypoperfusion: experiment with aged rats. Zhonghua. Yi. Xue. Za. Zhi 87(2), 2515-2517 (2007).

60. Ye J, Pi R, Mao X, et al. Alterations in mRNA expression of BACE1, cathepsin B, and glutaminyl cyclase in mice ischemic brain. NeuroRe port 20(1), 1456-1460 (2009).

61. Tanimukai H, Imaizumi K, Kudo T et al. Alzheimer-associated presenilin-1 gene is induced in gerbil hippocampus after transient ischemia. Mol. Brain. Res 54(2), 212-218 (1998).

62. Pennypacker KR, Hernandez H, Benkovic S, et al. Induction of presenilins in the rat brain after middle cerebral arterial occlusion. Brain. Res. Bull 48(5), 539-543 (1999).

63. Ułamek-Kozioł M, Kocki J, Bogucka-Kocka A, et al. Autophagy, mitophagy and apoptotic gene changes in the hippocampal CA1 area in a rat ischemic model of Alzheimer's disease. Pharmacol. Rep 69(6), 1289-1294 (2017).

64. Ułamek-Kozioł M, Kocki J, Bogucka-Kocka A, et al. Dysregulation of autophagy, mitophagy and apoptotic genes in the medial temporal lobe cortex in an ischemic model of Alzheimer's disease. J. Alzheimers. Dis 54(1), 113-121 (2016).

65. Ułamek-Kozioł M, Furmaga-Jabłońska W, Januszewski S, et al. Neuronal autophagy: self-eating or self-cannibalism in Alzheimer's disease. Neurochem. Res 38(9), 1769-1773 (2013).

66. Scheff SW, Price DA, Schmitt FA, et al. Synaptic loss in the inferior temporal gyrus in mild cognitive impairment and Alzheimer's disease. J. Alzheimers. Dis 24(3), 547-557 (2011).

67. Pluta R, Salińska E, Puka M, et al. Early changes in extracellular amino acids and calcium concentrations in rabbit hippocampus following complete 15-min cerebral ischemia. Resuscitation 16(1), 193-210 (1988).

68. Ni JW, Matsumoto K, Li HB, et al. Neuronal damage and decrease of central acetylcholine level following permanent occlusion of bilateral common carotid arteries in rat. Brain. Res 673(2), 290-296 (1995).

69. Ruan YW, Han XJ, Shi ZS, et al. Remodeling of synapses in the CA1 area of the hippocampus after transient global ischemia. Neuroscience 218(1), 268-277 (2012).

70. Hofmeijer J, van Putten MJ. Ischemic cerebral damage: an appraisal of synaptic failure. Stroke 43(2), 607-615 (2012).

71. Curcio M, Salazar IL, Mele M, et al. Calpains and neuronal damage in the ischemic brain: The swiss knife in synaptic injury. Prog.
Neurobiol 143(1), 1-35 (2016).

72. Fernando MS, Simpson JE, Matthews F, et al. White matter lesions in an unselected cohort of the elderly: molecular pathology suggests origin from chronic hypoperfusion injury. Stroke, 37: 1391-1398 (2006).

73. Scherr M, Trinka E, Mc Coy M, et al. Cerebral hypoperfusion during carotid artery stenosis can lead to cognitive deficits that may be independent of white matter lesion load. Curr. Neurovasc. Res 9(3), 193-199 (2012).

74. Thiebaut de Schotten M, Tomaiuolo F, Aiello $M$, et al. Damage to white matter pathways in subacute and chronic spatial neglect: a group study and 2 single-case studies with complete virtual "in vivo" tractography dissection. Cereb. Cortex 24(3), 691-706 (2014).

75. Wakita $\mathrm{H}$, Tomimoto $\mathrm{H}$, Akiguchi l, et al. Glial activation and white matter changes in the rat brain induced by chronic cerebral hypoperfusion: an immunohistochemical study. Acta. Neuropathol 87(5), 484-492 (1994).

76. Yoshizaki K, Adachi K, Kataoka S, et al. Chronic cerebral hypoperfusion induced by right unilateral common carotid artery occlusion causes delayed white matter lesions and cognitive impairment in adult mice. Exp. Neurol 210(2), 585-591 (2008).

77. Pluta R, Barcikowska M, Januszewski S, et al. Evidence of blood-brain barrier permeability/ leakage for circulating human Alzheimer's ß-amyloid-(1-42)-peptide. NeuroReport 7(1), 261-265 (1996).

78. Pluta R, Barcikowska M, Misicka A, et al. Ischemic rats as a model in the study of the neurobiological role of human $\beta$-amyloid peptide. Time-dependent disappearing diffuse amyloid plaques in brain. NeuroReport 10(1), 3615-3619 (1999).

79. Pluta R, Misicka A, Barcikowska M, et al. Possible reverse transport of $\beta$-amyloid peptide across the blood-brain barrier. Acta. Neurochir 76(Suppl), 73-77 (2000).

80. Anfuso CD, Assero G, Lupo G, et al. Amyloid beta (1-42) and its beta (25-35) fragment induce activation and membrane translocation of cytosolic phospholipase A (2) in bovine retina capillary pericytes. Biochim. Biophys. Acta 1686(1), 125-138 (2004).

81. Jabłoński M, Maciejewski R, Januszewski S, et al. One year follow up in ischemic brain injury and the role of Alzheimer factors. Physiol. Res 60(Suppl. 1), 113-119 (2011).

82. Austin BP, Nair VA, Meier TB, et al. Effects of hypoperfusion in Alzheimer's disease. J. Alzheimers. Dis 26(Suppl. 3), 123-133 (2011).

83. Pluta R. Ischemia-reperfusion pathways in Alzheimer's disease. New York, USA: Nova Science Publishers (2007). 